\title{
Ultrasound-guided plugged percutaneous biopsy of solid organs in patients with bleeding tendencies
}

\author{
WK Tsang *, WH Luk, Adrian XN Lo *
}

\section{A B S T R A C T}

Objective: To establish and verify the utility of plugging biopsy tracts, using a combination of Gelfoam slurry and torpedo in the prevention of post-biopsy bleeding in patients at high risk of post-procedure haemorrhage following ultrasoundguided percutaneous biopsy of solid organs.

Design: Case series.

Setting: Radiology Department of a regional hospital in Hong Kong.

Patients: In our unit, all patients considered to be at high risk of post-biopsy haemorrhage of a solid organ underwent ultrasound-guided plugged percutaneous biopsy from year 2005 to 2012.

Interventions: All the included patients had undergone real-time ultrasound-guided biopsy of solid organs (liver in 10 and spleen in one patient). In all cases, a combination of a coaxial introducer needle and Temno needle were used. After adequate specimens were obtained, Gelfoam slurry (for distal embolisation) followed by Gelfoam torpedo (for proximal embolisation) were used to plug the biopsy tract. post-biopsy haemorrhage treated by transfusion or other intervention, and plugging-related complications were reviewed for each patient.

Results: Technical success was achieved in all patients and none experienced post-biopsy haemorrhage treated by blood transfusion or any other intervention.

Conclusion: Plugging of the biopsy tract with Gelfoam slurry followed by Gelfoam torpedo is a direct and simple procedure that can safely and effectively prevent haemorrhage in patients at high risk of post-biopsy haemorrhage.

\section{Hong Kong Med J 2014;20:107-12}

DOI: $10.12809 / \mathrm{hkmj} 133972$

\author{
WK Tsang *, MB, ChB, FRCR \\ ${ }^{2}$ WH Luk, FRCR, FHKAM (Radiology) \\ ${ }^{2}$ AXN LO ", FRCR, FHKAM (Radiology) \\ Department of Radiology and Nuclear Medicine, Tuen Mun Hospital, \\ Tuen Mun, Hong Kong \\ 2 Department of Radiology and Organ Imaging, United Christian Hospital,
} Kwun Tong, Hong Kong

* Corresponding author: tsang_k@yahoo.com.hk

Main outcome measures: Technical success, any " DrAXN Lo is currently in private practice

New knowledge added by this study

- Plugging of the biopsy tract using a combination of Gelfoam slurry followed by Gelfoam torpedo is a new technique that has not been previously described.

Implications for clinical practice or policy

- Plugging of the biopsy tract using a combination of Gelfoam slurry and torpedo is safe and easy to undertake and should be used in patients at high risk of post-biopsy haemorrhage.

\section{Introduction}

Ultrasound-guided percutaneous biopsy is a wellestablished means for diagnosis of focal or diffuse disease in solid organs. It is generally safe and confers minimal risk of complications. However, it is contra-indicated in patients with bleeding tendencies, which means that histological diagnosis may be lacking and sometimes life-saving treatment cannot be commenced. Plugging of the biopsy tract is a promising technique to decrease the risk of post-biopsy haemorrhage, for which Gelfoam is the most commonly used agent. In this article, we share our experience in performing this procedure using Gelfoam slurry followed by Gelfoam torpedo in patients at high risk of post-procedure haemorrhage in our institution.

\section{Methods}

The Department of Radiology and Organ Imaging, United Christian Hospital, is the main radiology training centre of the Kowloon East Cluster, Hong Kong. Apart from diagnostic imaging, we provide both emergency and elective interventional radiology services. In the form of a retrospective study approved by our local ethics committee, since 2005, it has been our standard practice to plug the biopsy tract in all patients considered at risk of haemorrhage after having ultrasound-guided percutaneous biopsy 


\section{對高出血風險患者於超聲引導器官穿刺活檢後 進行活檢道堵塞 \\ 曾慧勤、陸永恆、羅煦寧}

目的：鍳於部份病人在進行超聲引導器官穿刺活檢後出現術後出血的 風險較高, 本研究旨在驗證合併使用明膠海綿亳和海綿條能否預防此 類風險出現。

設計：病例系列。

安排：香港一所分區醫院的放射科。

患者：從2005到2012年期間, 於上述醫院進行超聲引導器官穿刺活 檢並被評估為有高出血風險的患者。

介入：所有患者均進行實時超聲引導穿刺活檢, 包括肝臟 10 例和脾 藏 1 例。所有病例均同時使用同軸導引針和Temno針。取得足夠樣本 後, 合併使用明膠海綿膏（作遠端栓塞）及明膠海綿條（作近端栓 塞）將活檢道堵塞。

主要結果測量：每個病例的技術成功率、有否活檢後出血而需輸血或 治療, 以及與活檢道堵塞相關的併發症。

結果：所有病例均達至技術成功, 並無病人於活檢後出血而須接受輸 血或介入治療。

結論：合併使用明膠海綿膏和海綿條堵塞活檢道是一種直接和簡單的 防止出血方法, 對於活檢後有高出血風險的患者來説既安全又有效。

of a solid organ. Our departmental registry recorded all the cases receiving plugged percutaneous biopsy (PPB) of solid organs performed from 1 January 2005 to 30 September 2012. There was no reported refusal of the procedure by any patient. Demographic data, indication for the biopsy and for plugging of the biopsy tract, details of the biopsy technique, biopsy results, and any episodes of post-biopsy haemorrhage treated by transfusion or any other type of intervention were reviewed for each patient. Relevant details are listed in Table 1.

\section{Technique}

All PPBs were performed under strict aseptic conditions with instruments as shown in Figure 1. A biopsy path avoiding critical structures and major vessels was selected under ultrasound guidance. The length of the biopsy path starting from the organ capsule to the target region was measured (Fig 2a). A strip of Gelfoam of the same length and with a width of approximately $2 \mathrm{~mm}$ was cut from a sheet of Gelfoam. Before being cut, the sheet of Gelfoam was compressed manually to expel all air bubbles. A Gelfoam torpedo was formed by rolling the strip of Gelfoam into a rod-like structure (Fig 2b). The remaining Gelfoam sheet was then cut into tiny pledgets of around 2 $\mathrm{mm} \times 2 \mathrm{~mm}$ in size. A syringe filled with Gelfoam pledgets and another syringe filled with saline were both connected to a 3-way stopcock. Macerating the suspension with two syringes and a 3-way stopcock allowed further decreases in size of the pledgets into a slurry (Fig 2c). After the Gelfoam torpedo and slurry were ready, the puncture site was injected with local anaesthetic $(5-10 \mathrm{~mL}$ of $1-2 \%$ lignocaine) and a small skin incision was created. Patients were then instructed to hold their breath while a coaxial introducer needle (17G or 19G,

TABLE I. Details of patient demographic data, indication for plugged biopsy, biopsy site and technique, and pathological results

\begin{tabular}{|c|c|c|c|c|c|c|c|c|}
\hline $\begin{array}{l}\text { Pa- } \\
\text { tient } \\
\text { No. }\end{array}$ & $\begin{array}{c}\text { Sex/ } \\
\text { age } \\
\text { (years) }\end{array}$ & Indication of biopsy & $\begin{array}{l}\text { Biopsy } \\
\text { site }\end{array}$ & Reason for plugged biopsy & $\begin{array}{c}\text { Needle size } \\
\text { (coaxial/ } \\
\text { Temno } \\
\text { needle in G) }\end{array}$ & $\begin{array}{c}\text { No. of } \\
\text { needle } \\
\text { pass(es) }\end{array}$ & $\begin{array}{l}\text { Com- } \\
\text { plication }\end{array}$ & Pathology \\
\hline 1 & $\mathrm{~F} / 66$ & $\begin{array}{l}\text { Liver failure, suspected } \\
\text { autoimmune hepatitis }\end{array}$ & Liver & $\mathrm{INR}=1.7, \mathrm{APTT}=42.6 \mathrm{~s}$ & $17 / 18$ & 2 & No & Autoimmune hepatitis \\
\hline 2 & $M / 69$ & Liver mass & Liver & INR=1.4 & $19 / 20$ & 3 & No & $\begin{array}{l}\text { Adenocarcinoma } \\
\text { metastasis }\end{array}$ \\
\hline 3 & $M / 58$ & Liver mass & Liver & Active oozing from biopsy tract & $17 / 18$ & 1 & No & Hepatocellular carcinoma \\
\hline 4 & $\mathrm{~F} / 72$ & Liver mass & Liver & Active oozing from biopsy tract & $17 / 18$ & 2 & No & Stereo-hepatitis \\
\hline 5 & $F / 54$ & $\begin{array}{l}\text { Suspected autoimmune } \\
\text { hepatitis }\end{array}$ & Liver & INR=1.3, APTT=37.2 s & $19 / 20$ & 3 & No & Chronic hepatitis \\
\hline 6 & $\mathrm{~F} / 40$ & Suspected cirrhosis & Liver & $\mathrm{INR}=1.4, \mathrm{PIt}=90 \times 10^{9} / \mathrm{L}$ & $17 / 18$ & 3 & No & $\begin{array}{l}\text { Chronic hepatitis with } \\
\text { cirrhosis }\end{array}$ \\
\hline 7 & $\mathrm{~F} / 69$ & Suspected liver amyloidosis & Liver & Active oozing from biopsy tract & $17 / 18$ & 3 & No & Cirrhosis \\
\hline 8 & $\mathrm{~F} / 74$ & Splenic mass & Spleen & Hypervascular biopsy organ & $19 / 20$ & 1 & No & Burkitt-like lymphoma \\
\hline 9 & $F / 29$ & Suspected cirrhosis & Liver & $\begin{array}{l}\text { INR=1.4, APTT=38 s, } \\
P I t=70 \times 10^{9} / \mathrm{L}\end{array}$ & $17 / 18$ & 3 & No & Lymphocytic infiltrates \\
\hline 10 & $\mathrm{M} / 47$ & $\begin{array}{l}\text { PUO, PET-CT } \\
\text { hypermetabolic liver }\end{array}$ & Liver & $\begin{array}{l}\text { INR=1.5, APTT=50.6 s, } \\
\mathrm{Plt}=62 \times 10^{9} / \mathrm{L}\end{array}$ & $17 / 18$ & 4 & No & Tuberculosis \\
\hline 11 & $F / 58$ & Liver mass & Liver & Active oozing from biopsy tract & $17 / 18$ & 3 & No & Hepatocellular carcinoma \\
\hline
\end{tabular}

Abbreviations: APTT = activated partial thromboplastin time; INR = international normalised ratio; PET-CT = positron emission tomography-computed tomography; PIt = platelet count; $\mathrm{PUO}=$ pyrexia of unknown origin 
CareFusion; Waukegan [IL], US) was advanced to the target region. The stylet of the coaxial introducer needle was removed, with the outer sheath held firmly in place. A Temno biopsy needle (18G or 20G, CareFusion) was then inserted through the sheath under ultrasound guidance. Biopsy specimens were obtained in a standard manner. After removal of the Temno needle between passes, the stylet of the coaxial introducer needle was reinserted into the sheath to decrease the chance of haemorrhage. After adequate specimens were obtained by inspection, 1 to $2 \mathrm{~mL}$ of Gelfoam slurry was injected into the sheath of the coaxial introducer needle (Fig 3). The Gelfoam torpedo was then placed at the hub of the sheath of the coaxial introducer needle (Fig 4a) and pushed by the stylet until the echogenic tip of the stylet was advanced to the organ capsule (Fig 4b). The outer sheath was then withdrawn while keeping the stylet still (Fig 4c), so that the Gelfoam torpedo could be deployed along it and therefore sealing the biopsy tract. Finally, the entire coaxial introducer needle was removed.

\section{Results}

During a 7-year period, we performed 11 cases of plugged percutaneous solid organ biopsy in 11 patients, all of whom were considered at high risk of post-biopsy bleeding due to the reasons listed in Table 1 . The mean patient age was 58 (standard deviation $[S D], 14)$ years. Three patients were male and eight were female. The target organ was the liver in 10 cases and the spleen in one. The indications for biopsy were to achieve a diagnosis of a focal mass in five cases, and characterisation of diffuse hepatic diseases in six (Table 1). The number of needle passes ranged from one to four, with a mean of 2.5 (SD, 0.9). In all cases, the combination of a coaxial introducer needle and Temno needle (both by CareFusion) were used. The combination of a $17 \mathrm{G}$ coaxial introducer needle and 18G Temno needle was used in eight biopsies, while the combination of a 19G coaxial introducer needle and 20G Temno needle was used thrice. All the biopsies were technically successful in obtaining adequate specimens for a histological diagnosis. None of the patients experienced postbiopsy haemorrhage treated by transfusion or any other form of intervention.

\section{Discussion}

Ultrasound-guided percutaneous solid organ biopsy is a well-established means of diagnosing focal or diffuse disease in solid organs. In general, it is safe and confers minimal risk of complications. Major and minor complication (mainly bleeding) rates of $0.8 \%$ and $2-3.8 \%$, respectively, have been reported., ${ }^{1,2}$ Many factors increase the risk of post-biopsy haemorrhage, which can be divided into lesional, technical, and patient-related. Lesional factors consist of

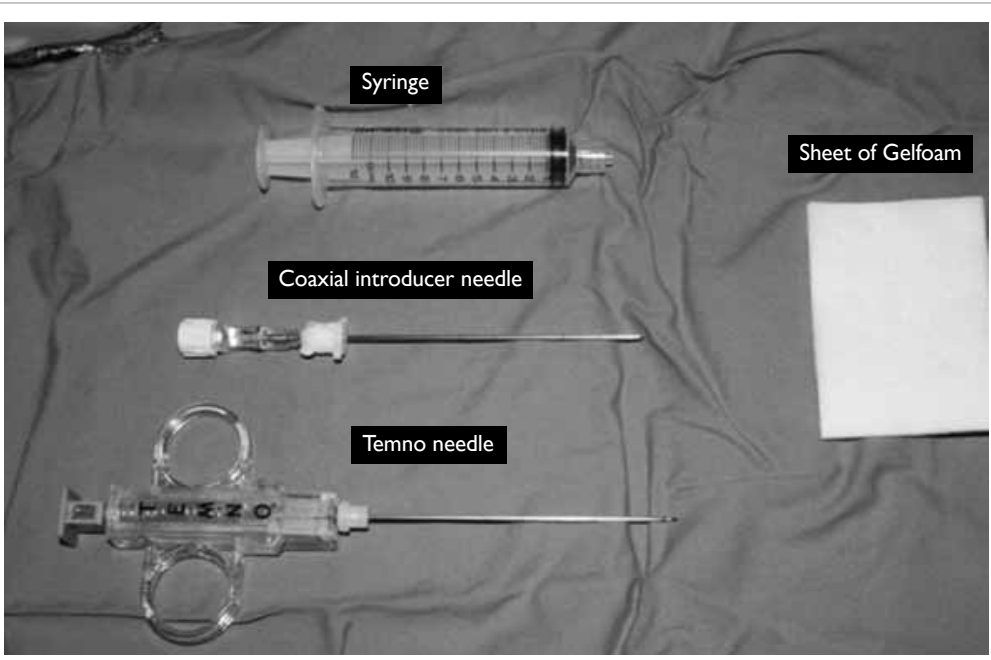

FIG I. Instruments needed in plugged percutaneous biopsy
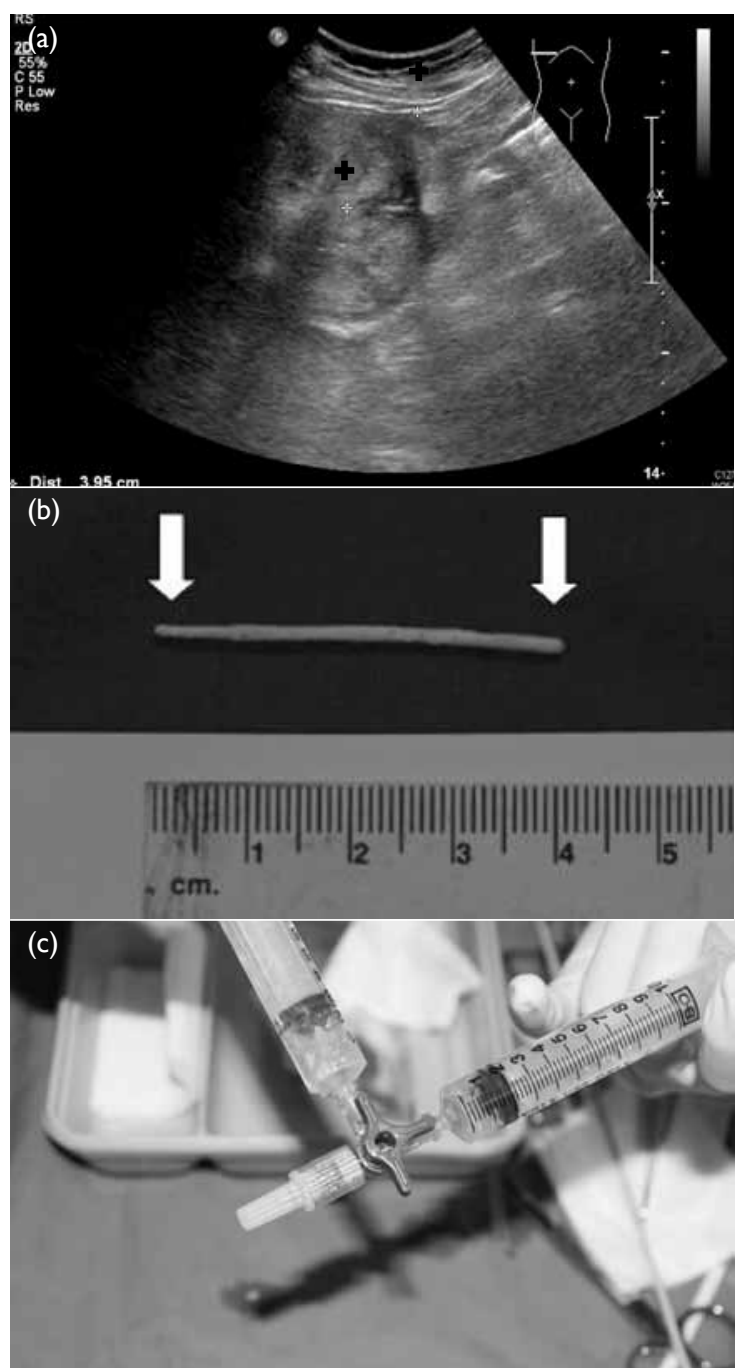

FIG 2. (a) The length of the biopsy path starting from the organ capsule to the target region is measured on ultrasonography. (b) A strip of Gelform of the same length with a width of $2 \mathrm{~mm}$ is cut from a sheet of Gelfoam. It is then rolled into a rod-like structure (torpedo). (c) Macerating the suspension of Gelfoam with two syringes and a 3-way stopcock allows further decrease in size of the pledgets 


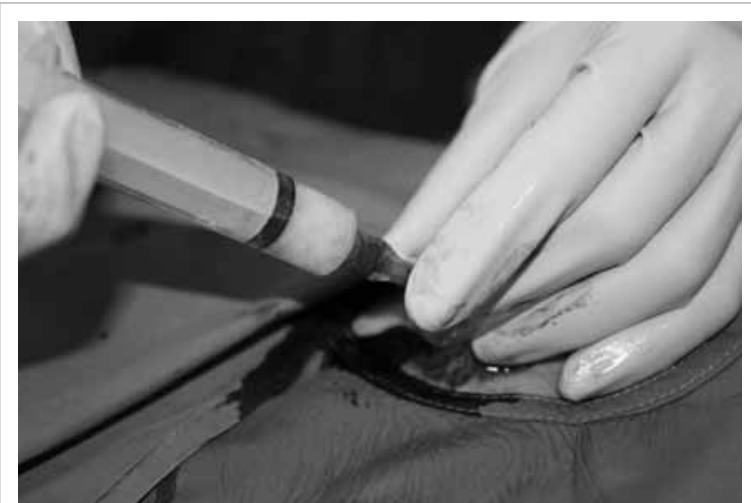

FIG 3. After adequate specimens are taken, I-2 $\mathrm{mL}$ of Gelfoam slurry is injected to the sheath of coaxial introducer needle
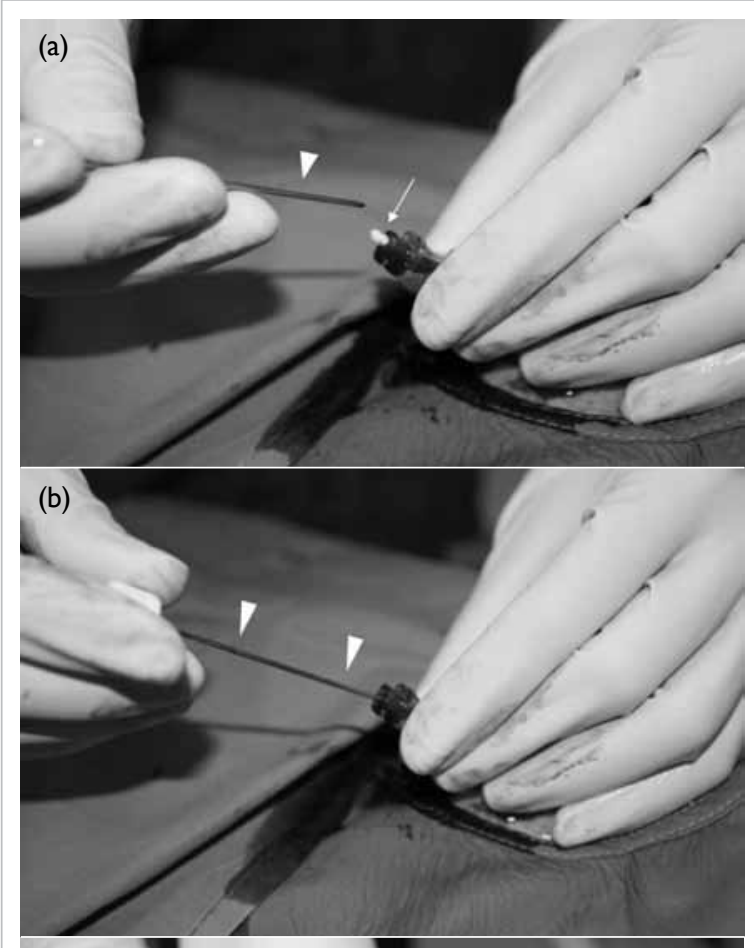

(c)

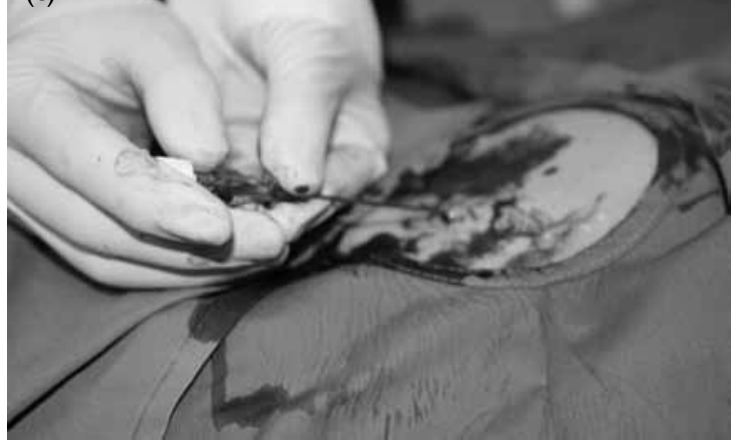

FIG 4. (a) Gelfoam torpedo (arrow) is placed at the hub of the coaxial introducer needle. (b) Gelfoam torpedo is then pushed by the stylet of the coaxial introducer needle (arrowheads). (c) The outer sheath of the coaxial introducer needle is withdrawn with the stylet stays still so that the Gelfoam torpedo can be deployed and seals the biopsy tract peripheral subcapsular location, close proximity to major vessels, hypervascularity, and hypervascular biopsy sites (such as the spleen). Technical factors include increased numbers of needle passes, large needle sizes, use of cutting needles, blind biopsies, and less-experienced operators. ${ }^{3}$ Patient factors include coagulopathy, platelet dysfunction or thrombocytopenia, medications (eg antiplatelet agents and anticoagulants), chronic liver disease, haematological malignancy, presence of moderateto-severe ascites, and uncooperative patients. ${ }^{2,4,5}$ Some studies showed that peripheral blood coagulation indices have a poor correlation with liver bleeding time following laparoscopic biopsy, which might be caused by low regional platelet counts, clotting factor deficiencies in the liver parenchyma, and the lack of mechanical compression of the biopsy tract by inelastic tissue (eg cirrhotic liver). ${ }^{6}$ Therefore operators should always be prepared for the possibility of significant post-biopsy haemorrhage, even in patients with normal clotting profiles and platelet counts.

Obviously, the main contra-indication to image-guided percutaneous solid organ biopsy is a bleeding diathesis. ${ }^{2}$ However, histological diagnosis is critical and even lifesaving, by means of achieving correct treatment. In the past, transjugular liver biopsy had been advocated in patients with bleeding diathesis, massive ascites, and poor respiratory control. ${ }^{7,8}$ However, this has multiple disadvantages. In particular, it is not feasible for liver lesions far from the major hepatic veins. Moreover, it is technically demanding and associated with a high rate of insufficient specimen retrieval for satisfactory histological examination (11.2-29\%).,9-12 It can also give rise to complications at the puncture site (jugular vein) and induce arrhythmias during right atrial passage. Haemoperitoneum is possible if the liver capsule is perforated, which can sometimes be fatal.

Plugged percutaneous biopsy is an alternative to transjugular liver biopsy in patients at high risk of bleeding. ${ }^{2,8,13}$ It was first described by Riley et al in $1984 .^{13}$ In plugged biopsy, the tract is embolised (plugged) after the percutaneous biopsy, thus decreasing the risk of haemorrhage. Multiple studies on PPB have demonstrated at least a 95\% success rate in obtaining adequate specimens for histological diagnoses. It is also a safe procedure with a complication rate of less than $2 \%$ (Table $\left.2^{7-9,14-16}\right)$. It has the obvious advantages of being direct and can be used to biopsy focal hepatic lesions away from major hepatic veins and in other organs. Also, a larger biopsy needle can be used, which increases the chance of obtaining adequate specimens. Finally, it does not involve the vascular system or passage through the right atrium and thus the relevant complications can be avoided. 
TABLE 2. Comparison of the results of various plugged biopsy studies

\begin{tabular}{lccccc}
\hline Study & No. of biopsies & $\begin{array}{c}\text { No. (\%) of diagnostic } \\
\text { samples }\end{array}$ & Embolic agent & Needle type & $\begin{array}{c}\text { No. (\%) of } \\
\text { complications }\end{array}$ \\
\hline Tobin and Gilmore, ${ }^{14} 1989$ & 100 & $100(100)$ & Gelatin sponge & Tru-cut & $0(0)$ \\
\hline Zins et al, ${ }^{7} 1992$ & 78 & $74(95)$ & Gelatin sponge and thrombin & Sure-cut & $2(2)$ \\
Sawyerr et al, ${ }^{15} 1993$ & 56 & $55(98)$ & Gelatin sponge & Biopty-cut & $2(4)$ \\
\hline Smith et al, ${ }^{16} 1996$ & 80 & $80(100)$ & Gelatin sponge & Tru-cut & $6(8)$ \\
\hline Kamphuisen et al ${ }^{9}, 2002$ & 39 & $39(100)$ & Ivalon & Tru-cut & $0(0)$ \\
Atar et al, ${ }^{8}$ 2010 & 233 & $231(99)$ & Gelatin sponge & Quick-core & $0(0)$ \\
Total & $\mathbf{5 8 6}$ & $\mathbf{5 7 9 ( 9 9 )}$ & - & - & $\mathbf{1 0}(\mathbf{1 . 7})$ \\
\hline
\end{tabular}

The most commonly used embolic agent is Gelfoam, which is an absorbable compressed gelatin sponge prepared from purified porcine skin. ${ }^{3,7}$ It is capable of absorbing up to 45 times its weight of whole blood, and induces haemostasis by speeding up thrombus formation and providing structural support for the clot. Gelfoam is a temporary embolic agent, which is usually completely absorbed within a few days or weeks, depending on the amount used, the degree of saturation with blood, and the application site. It is widely used in tract plugging as it is relatively inexpensive and readily available. It is easy to use and can be prepared in different forms, depending on the site of application. In our centre, Gelfoam was prepared in the form of torpedo and slurry. The Gelfoam torpedo was made from tight rolling of a small strip and used at the site of active bleeding. Due to their larger size, Gelfoam torpedoes can remain at the site of deployment instead of being flushed away by blood. The drawback of the torpedo is that distal embolisation cannot be achieved. In contrast, Gelfoam slurry is suitable for distal embolisation. It can be prepared by mixing tiny Gelfoam pledgets with contrast or saline. Further decrease in size of the pledgets can be created by macerating the suspension with two syringes and a 3-way stopcock. The syringe should be held nose up as Gelfoam floats in fluid. The disadvantage of slurry is that it is difficult to deploy at sites of active bleeding, as the suspension can be flushed away by blood. In our centre, we injected Gelfoam slurry first for distal embolisation and then filled up the rest of the biopsy tract with a torpedo. To the best of our knowledge, plugging of the biopsy tract using a combination of Gelfoam slurry followed by Gelfoam torpedo is a new technique that has not been previously described. Gelfoam is safe to use most of the time, although there is a minute risk of non-targeted embolisation of the biliary or vascular systems and of becoming a nidus for microbial growth. ${ }^{3}$

Apart from plugging of the biopsy tract, there are other measures to decrease the risk of bleeding in patients undergoing solid organ biopsy.
First, as appropriate, we should try to correct any coagulopathy by administration of fresh frozen plasma, platelets, coagulation factors, and vitamin K, whilst also withholding antiplatelet or anticoagulant medications if at all feasible. Although not related to the bleeding risk, red cell or whole blood transfusion should be given before the biopsy to significantly anaemic patients. Next, careful planning of the method of biopsy is important. A safe biopsy path not traversing vessels or critical structures should be sought. Leaving adequate distance of normal parenchyma from the organ capsule and the biopsy site can also help mechanical compression of the biopsy tract by virtue of tissue elasticity, after the needle is removed. We have to strike a balance between the tissue yield and the use of smaller needles. The use of a coaxial system allows multiple needle passes with just a single puncture. Reducing ascites, if present with diuretics or paracentesis, can also decrease the risk of haemorrhage.

One limitation of our study was the small sample size. Second, it was a retrospective observational study without a control group. A largescale prospective randomised controlled study may be ideal to validate the efficacy and safety of PPB. We share our experience in this small-scale study to raise the awareness of this procedure (especially for those not specialised in interventional radiology), as it shows that PPB is a simple and safe method with a high technical success rate that can help prevent post-biopsy haemorrhage.

\section{Conclusion}

Plugging of the biopsy tract with Gelfoam slurry followed by a Gelfoam torpedo is a direct, simple, safe, and effective means of preventing haemorrhage in patients at high risk of post-biopsy haemorrhage.

\section{References}

1. Hatfield MK, Beres RA, Sane SS, Zaleski GX. Percutaneous imaging-guided solid organ core needle biopsy: coaxial versus non coaxial method. AJR Am J Roentgenol 2008;190:413-7.

2. Albéniz Arbizu E, López San Román A, Garcia González 
M, et al. Fibrin-glue sealed liver biopsy in patients with a liver transplantation or in liver transplantation waiting list: preliminary results. Transplant Proc 2003;35:1911-2.

3. Azar N, Delman T, Nakamoto D. Transcutaneous management of bleeding after solid organ biopsy what the radiologist needs to know and use. US Radiology 2011;3:53-6.

4. Chuah SY. Liver biopsy-past, present and future. Singapore Med J 1996;37:86-90.

5. Sherlock S, Dick R, Van Leeuwen DJ. Liver biopsy today. The Royal Free Hospital Experience. J Hepatol 1984;1:7585.

6. Ewe K. Bleeding after liver biopsy does not correlate with indices of peripheral coagulation. Dig Dis Sci 1981;26:38893.

7. Zins M, Vilgrain V, Gayno S, et al. US-guided percutaneous liver biopsy with plugging of the needle track: a prospective study in 72 high-risk patients. Radiology 1992;184:841-3.

8. Atar E, Ben Ari Z, Bachar GN, et al. A comparison of transjugular and plugged-percutaneous liver biopsy in patients with contraindications to ordinary percutaneous liver biopsy and an "in-house" protocol for selecting the procedure of choice. Cardiovasc Intervent Radiol 2010;33:560-4.

9. Kamphuisen PW, Wiersma TG, Mulder CJ, de Vries RA. Plugged-percutaneous liver biopsy in patients with impaired coagulation and ascites. Pathophysiol Haemost Thromb 2002;32:190-3.

10. Lebrec D, Goldfarb G, Degott C, Rueff B, Benhamou JP. Transvenous liver biopsy: an experience based on 1000 hepatic tissue samplings with this procedure. Gastroenterology 1982;83:338-40.

11. Velt PM, Choy OG, Shimkin PM, Link RJ. Transjugular liver biopsy in high-risk patients with hepatic disease. Radiology 1984;153:91-3.

12. Wolska-Krawczyk M, Krawczyk M, Katoh M, et al. Liver fibrosis: how many samples in transjugular liver biopsy are sufficient? Histological vs. clinical value. Abdom Imaging 2013;38:461-4.

13. Riley SA, Ellis WR, Irving HC, Lintott DJ, Axon AT, Losowsky MS. Percutaneous liver biopsy with plugging of needle track: a safe method for use in patients with impaired coagulation. Lancet 1984;2:436.

14. Tobin MV, Gilmore IT. Plugged liver biopsy in patients with impaired coagulation. Dig Dis Sci 1989;34:13-5.

15. Sawyerr AM, McCormick PA, Tennyson GS, et al. A comparison of transjugular and plugged-percutaneous liver biopsy in patients with impaired coagulation. J Hepatol 1993;17:81-5.

16. Smith TP, McDermott VG, Ayoub DM, Suhocki PV, Stackhouse DJ. Percutaneous transhepatic liver biopsy with tract embolization. Radiology 1996;198:769-74. 